\title{
The Responsibility of the Faculty Members of Yarmouk University in Achieving Quality in Higher Education
}

\author{
Adnan B Al-Ibrahim, Amjad M Daradkah", \\ ${ }^{1}$ Department of Management and Foundations of Education, Faculty of Education, Yarmouk University, Jordan \\ ${ }^{2}$ Department of Administration and Curriculum, Faculty of Educational Sciences, Ajloun University, Ajloun, Jordan
}

Received December 18, 2020; Revised February 20, 2021; Accepted March 12, 2021

\begin{abstract}
Cite This Paper in the following Citation Styles
(a): [1] Adnan B Al-Ibrahim, Amjad M Daradkah, "The Responsibility of the Faculty Members of Yarmouk University in Achieving Quality in Higher Education," Universal Journal of Educational Research, Vol. 9, No. 5, pp. 1037 - 1043, 2021. DOI: 10.13189/ujer.2021.090516.
\end{abstract}

(b): Adnan B Al-Ibrahim, Amjad M Daradkah (2021). The Responsibility of the Faculty Members of Yarmouk University in Achieving Quality in Higher Education. Universal Journal of Educational Research, 9(5), 1037 - 1043. DOI: 10.13189/ujer.2021.090516.

Copyright $\odot 2021$ by authors, all rights reserved. Authors agree that this article remains permanently open access under the terms of the Creative Commons Attribution License 4.0 International License

\begin{abstract}
The current study identifies the responsibility of the faculty members at Yarmouk University in achieving quality in higher education. To achieve the objectives of the study, the descriptive-analytical method is employed. The study sample consists of the faculty members at Yarmouk University in the academic year 2019-2020. The results show that the quality of higher education depends on the quality of the faculty member's performance and has several basic determinants, including mastery, righteous deed, and beneficence. The results also show that to achieve quality in the faculty member's performance, a large number of requirements shall be met such as sincerity and loyalty at work, advantageous work, working as best as possible. Moreover, it is found that quality in education is reached through the efforts made by senior university management and faculty members. Besides, the results also show that to reach accreditation at universities, individual and collective responsibility is required. The results also show that the administration of the university is also responsible, namely: the faculty members are obligated to teach, conduct research, and serve the society with utmost quality. Furthermore, it is found that the government, i.e. the Accreditation Board is required to monitor universities and ensure that they achieve quality in teaching, conducting research, and serving the community and society.
\end{abstract}

Keywords Quality, Responsibility, Higher Education Institutions, Faculty Member

\section{Introduction}

The concept of total quality management is not only applied to institutions that aim to make a profit, but to those whose aim is to improve the quality of education. The latter institutions also aim to enable students to improve and enhance society. Higher educational institutions are the driving force of society whose output is considered the input of all industrial, productivity, and even service institutions. This is because they provide the building blocks for creativity, innovation, and improvement of human skills. Furthermore, higher education institutions increase individuals' capabilities, enabling them to interact with and adapt to the output of these institutions (Abo Daf, 2007).

Therefore, the quality of education can be raised by making a clear policy on the total quality, administrative management efficiency, and provision of high-quality training for administrative and faculty members. In Jordan, universities have high status, where they exist from the north to the south of the nation. In this country, education and knowledge have been well-improved, particularly as most of its universities have improved the quality of higher education to perform as best as possible and achieve the best results.

In today's world, universities have become the driving force for preparing and training individuals with various 
specializations and fields in society. For this reason, universities bear the greatest responsibility for improving and raising all levels of society and yet striving to continuously make academic improvement which is per the demands and changes of society. This is done in an attempt to enable students to achieve the greatest possible benefits and to improve the performance of faculty members, which will be consequently beneficial for themselves and society (Abo Daf, 2007).

Quality is defined as "how good or bad something is done while quality in education is defined as the accumulator of features and characteristics of education service which fulfills students' demands" (Cambridge Dictionary). Thus, the concept of quality in education is related to all characteristics and features of the field of education. This quality is about some demands and expectations of students related to their education and training, so they can be improved based on students' perspectives. Furthermore, educational quality is defined as improving the quality of education and making it more suitable to the individual as well as societal needs and making it more effective to achieve its objectives (Ali et al., 2016). Moreover, this term can be defined as the quality of educational performance to achieve a goal consistent with the nature and aim of the teaching process.

In their study, Steinhardt et al. (2016) have mapped the development and content of research in the literature regarding the quality assurance of teaching and learning. To this end, they carried out a bibliometric analysis of 1610 papers from approximately 400 journals over 17 years from 1996 to 2013. The results of this study reveal that the quality assurance of teaching and learning becomes a specialty. Also, educational quality is defined as many quantitative and qualitative indicators and scales that determine the degree of diversity within the educational system, and this, in turn, will modernize and improve society (Amajd, 2021).

The quality of education is related to both the objectives and sources and it aims to improve the objectives, input, processes, procedures, ways, techniques, and methods in the teaching process. All of these elements positively influence the final product, i.e. the student. Thus, those involved in education, especially universities, are supposed to know the demanded specializations in markets, make a long-term plan for them, and predict the demands of the local market. Faizan et al. (2016) have carried out a study to investigate the impact of Malaysian public universities' service quality on international student satisfaction, institutional image, and loyalty. The results of this study show that academic aspects significantly influence students' satisfaction. In other words, students, who have positive perceptions of academic aspects at university, attain higher levels of satisfaction.

Moreover, Seyfried and Pohlenz (2018) investigate the determinants of effectiveness in quality assurance at higher education institutions. The results of this study indicate that support by higher education institutions' higher management and cooperation with other education institutions are relevant prerequisites for larger perceived levels of quality assurance effectiveness. Furthermore, this study shows that quality managers' role as promoters of quality assurance is significantly correlated with perceived effectiveness. Furthermore, Hu et al. (2019) examine the evaluation process and quality assurance system in the higher vocational institution. Their findings suggest that to improve the quality of teaching in higher vocational schools, total quality management shall be implemented.

\subsection{Problem of the Study}

Higher education in Arab societies is still below the desired standard. Meanwhile, the Levant countries face major challenges in this respect. Despite the high attention paid to their universities in recent years, the results achieved by them are insignificant compared to the efforts being made. Therefore, it is crucial to improve the higher education system. Importantly, faculty members' performance at universities is not measured and corrected based on transparent, accurate, and objective standards. These standards guarantee the status that faculty members have at university. This is done through enhancing and improving their performance by being completely obligated to their duties preserving their pioneering role as they are the leaders of society. Society is also responsible for enabling them to improve and promote their performance. With that, the problem of the study lies in identifying the responsibility of the faculty members at Yarmouk University in achieving quality in higher education.

\subsection{Questions of the Study}

In light of the problem of the study, the following questions are articulated.

1. What is the responsibility of the faculty members at Yarmouk University in achieving quality higher education?

2. What are the methods and requirements of making the faculty members responsible for achieving quality higher education?

3. What are the challenges facing the faculty members in their attempt to apply the responsibility principle for achieving quality higher education?

\subsection{Objectives of the Study}

The following objectives are formatted to answer the questions of the study:

1. Identifying the responsibility of the faculty members at Yarmouk University in achieving quality higher education.

2. Identifying the methods and requirements of making the faculty members responsible for achieving quality higher education. 
3. Identifying the challenges facing the faculty members in their attempt to apply the responsibility principle for achieving quality higher education.

\subsection{Significance of the Study}

The significance of the study lies in identifying the responsibility of the faculty members at Yarmouk University in achieving quality higher education. Moreover, to the best of the researcher's knowledge, there is little Arab and world literature conducted in this area, where the library of the university as well as the Arab and foreign databases contains a very small number of similar studies. All of these show the significance of this study. Therefore, it is hoped that the present study can be beneficial for researchers to conduct similar studies based on the results and recommendations of this study.

\subsection{The Conceptual Definitions}

Quality: it is the efforts made by those involved in the field of education to improve and enhance the product of education. These efforts are to suit the beneficiary's desire, and capacities, and features of the educational product. Majid (2008) defines quality as a tool for performing appropriately and in accordance with a set of required educational criteria and features. Its aim is to raise the level of the educational product's quality by the fewest possible efforts and the most affordable costs. Moreover, the quality higher education will help achieve the objectives of the university, and this is done in accordance with the beneficiaries' satisfaction.

It is emphasized that quality is not about words, but it is rather about our behaviors. The most important part of this definition is that quality is to serve the beneficiaries----, i.e. students. Thus, quality has nothing to do with the number of scholarships and privileges, or the averages of scores of faculty members, or the number of books provided in the libraries. Rather, quality is about the attention paid to serve the individuals who are involved inside or outside the university (Ali et al., 2016).

Responsibility: it means asking individuals to accomplish the tasks they were asked to accomplish. In this case, one person is obligated to help the other and must accomplish a set of tasks. Otherwise, he or she will accept the resulting penalties (Abo Daf, 2007).

Higher education institutions: they are the universities, institutions, as well as the cultural and scientific colleges which adhere to the educational policy. This is done through providing university and higher education, and conducting studies, authoring books, carrying out translations, publication, and serving the society (Abo Daf, 2007).

\subsection{The Limits of the Study}

This study is limited to identifying the responsibility of faculty members at Yarmouk University in achieving quality in higher education for the academic year 2019-2020. It is also limited to the faculty members working at Yarmouk University.

\section{Methodology}

Due to the nature of this study, the descriptive-analytical method is employed as it is suitable for the nature of the study. To carry out this study and answer its questions, the four aspects are examined by using the descriptive-analytical method, namely: the quality of higher education, the responsibility of faculty members in achieving quality in higher education at Yarmouk University, the methods and requirements of achieving quality in higher education from the viewpoint of the faculty members, and the challenges faced by the faculty members in applying the responsibility principle to achieve quality.

\section{Discussion}

Based on the methodology adopted in this study, the discussion is articulated as follows:

\subsection{The Quality of Higher Education}

The quality in higher education can be defined as the features and characteristics which prepare the graduated individuals to fulfill the requirements of the market, the society, and all other institutions inside and outside the country. These institutions can raise the country's esteem. To achieve this quality, all individuals, systems, policies, and infrastructures shall facilitate a convenient circumstance, which in turn, help prepare the student. In this respect, the quality criteria required in higher education will be discussed. Fathieh (2007) emphasizes that the quality of higher education is a philosophy that universities must adopt to improve continuously. Therefore, the attention must be focused on students, beneficiaries, and the whole society.

Furthermore, the study conducted by Al-Harbi (2009) indicates that quality is a method that can be employed in different areas, including the area of education. Moreover, quality is naturally related to a large number of principles and basics, some of which are as follows: striving to fulfill the employee's satisfaction and continuously improve and encourage the employees. Achieving quality in education will benefit the student, the teacher, and the whole society. Quality is associated with 'perfection' and 'high value.' In other words, quality in higher education is a basic principle for educational institutions to achieve success, to improve education, and to help students in higher education reach their appropriate status and achieve their goals and success (Al-Andigani et al., 2007). 


\subsection{The Responsibility of Faculty Members in Achieving Quality in Higher Education at Yarmouk University}

To achieve quality, some requirements need to be fulfilled, one of which is that faculty members themselves must be qualified as they are an active element in achieving quality. Other requirements in achieving quality in education are mastery, beneficence, and goodness. Furthermore, to achieve quality in higher education, some criteria must be met such as learning a specialization requires all subjects to be covered in the curriculum. These subjects must necessarily be suitable for our everyday lives and the demands of the market. Moreover, this curriculum must develop students' analytical ability and help them to improve their thinking abilities, research and social skills, and various scientific and applied activities that improve students' personalities. There is also a necessity to prepare students for experiencing globalization through learning at least one foreign language. Also, another criterion is to choose the faculty members carefully and based on specific conditions and criteria, some of which are: the moral and scientific levels, patriotism, accepting feedback and constructive criticism, creating a sense of innovativeness, developing students' skills, and encouraging and supporting them, being obligated to the curriculum, and developing the spirit of research and thinking among students. This must be away from dictating, memorizing, and non-usage of the rational mind. Also, among these criteria are setting out transparent, clear goals for education in all educational institutions, and making the required plans for achieving these goals, along with providing the facilities required in education, so it can be provided for most individuals. Also, providing the facilities which add to the beauty of educational institutions is one criterion. By doing so, students, as well as faculty and administrative members, will enjoy mental comfort, and each member will be encouraged to accomplish his/her tasks as best as possible (Abo Daf, 2007).

Therefore, quality in higher education can be achieved if faculty members adopt the responsibility principle. As far as the researcher of the present study is concerned with having a sense of responsibility, faculty members' behaviors can be a model for administrative organizations in general and higher education institutions in particular. Having a sense of responsibility means that the faculty member is responsible for accomplishing the work he or she is assigned and considers God to be monitoring them. In other words, the faculty member is required to monitor himself to know his precise responsibilities. There are several requirements that the faculty member must meet to achieve quality in teaching higher education programs. These requirements are sincerity in the workplace, advantageous work, accomplishing the work as best as possible, and loyalty at work (Al-Andigani et al., 2007).

Therefore, it can be concluded that quality in higher education is related to the performance of the faculty members and there are some basic factors in this regard, including mastery, righteous deed, and beneficence. For the faculty member to perform with high quality, a large number of requirements must be met, including sincerity in the workplace, advantageous work, accomplishing the work as best as possible, and being loyal at work. Furthermore, controlling quality means that the faculty member is to be monitored, so he or she is obligated to achieving quality. This is done by being responsible (Al-Andigani et al., 2007).

Al-Khatib (2005) emphasizes that through the operations of controlling quality, management, production, and development can remain with high quality. These operations are followed through reliable plans. Meanwhile, the administration will lead such operations and any institution and all of its members will be responsible for achieving quality and making continuous improvement. Moreover, not making mistakes and being accurate will be considered in performance, such beneficiaries make a profit. The researcher of the present study believes that Al-Khatib's viewpoint is applied at Yarmouk University. This is done through monitoring as well as reprimanding all aspects of the faculty member's performance.

\subsection{The Methods and Requirements of Achieving Quality in Higher Education from the Viewpoint of the Faculty Members}

To make the faculty member responsible, he must monitor and control himself. Furthermore, he must be monitored by others which is a condition referred to as evaluation of the faculty member's performance. The faculty member must also be reprimanded by others. Reprimanding, controlling, and monitoring the faculty member's performance and identifying and improving his weaknesses are necessary. Furthermore, his strengths in all areas should be reinforced. These factors are determinant in achieving quality. Sense of responsibility must be present in two areas:

First of all, the faculty member must be obligated to monitor himself and feel that God is aware of everything. Thus, the basis for responsibility is the understanding that God observes the behaviors of human beings and will question him for these behaviors. Furthermore, the faculty member should well observe himself as his performance affects his teaching and research experiences, and will also affect his university and society. Such a person feels that he is being observed by God and on this basis, he will worship him (Al-Andigani et al., 2007).

Second, the faculty member should also be monitored by others. In other words, others have a responsibility towards the faculty member and the university. Since human nature is not infallible and it is likely to get deviated, it is apparent that responsibility is necessary. Thus, monitoring and correcting such deviation is the 
responsibility of those in charge of the faculty members' performance. The present study believes that to possess mastery and quality at work, monitoring and questioning as well as correcting the performance are all required. This is called quality control operation which is performed through controlling the quality of performance and having continuity in improving the quality of the faculty member's performance. Moreover, quality control involves identifying the positive and negative points done based on the responsibility principle. Among the methods employed to enable faculty members to achieve quality in higher education is accreditation which is an academic status that is accorded to educational institutions if they meet several criteria related to quality in education. Majid and Al-Ziadat (2008) defined accreditation as a scientific and institutional activity that aims at upgrading and promoting the level of educational institutions as well as academic programs. Moreover, accreditation is an influential and effective means for assuring the quality of education and its output and improvement.

A study carried out by Tamiyyeh and Al-Badri (2004) emphasizes that the primary and ultimate goal of adopting accreditation or academic recognition is to enable faculties to accomplish their duties (i.e. achieving quality) as best as possible. These duties can be summarized as follows: promoting and maintaining the quality of higher education, making all of the organizations' parties in the institutions liable and responsible, determining levels and criteria for assessing all aspects of the institution, determining the levels which meet the criteria for accreditation and academic recognition, and consolidating society's confidence in accredited institutions.

From what is previously presented, it can be obvious that there is a significant relationship between quality and accreditation. Also, Andibeigani and Niazi (2007) insist that there is a relationship between quality and accreditation, and to control quality, it must be proved that educational institutions can meet the quality standards in all of their administrative and educational sections. It can be concluded that to adopt accreditation, which is demanded by higher education institutions, it is necessary to possess mastery and quality at work and to gain continuous promotion, so the highest levels at universities can be reached. Moreover, the quality control operation means adopting the responsibility principle, leading to gaining accreditation for the university.

Accreditation is an academic status provided for the education institution in case it meets the quality criteria. Thus, it can be said that accreditation means overtly taking the responsibility to assure mastery and quality in performance. In this regard, Majid and Al-Ziadat (2008) show that most western countries consider accreditation to be a means to maintain quality. For this reason, these countries created boards, some of which were named 'the Accreditation Board' while others were named, 'the Assessment Board. The present study tries to emphasize that accreditation is the same as quality control and maintenance, which in turn, can be achieved once the administration, as well as the faculty members, accept the responsibility. In other words, accreditation and quality can be achieved only based on responsibility and through continuous training and questioning.

The researcher of this study believes that to achieve accreditation at universities, both individual and collective responsibility is required. Individual responsibility is that taken by faculty members in teaching, conducting research, and serving the university and society. Collective responsibility, however, is that taken by the administration to monitor faculty members' performance. They should assure that the faculty members teach, conduct research, and serve the university and society with utmost quality. In this regard, the governmental party, the Accreditation Board, also has responsibility, as it ascertains that the university performs with high quality in teaching, conducting research, and serving the society.

Birk et al. (2006) show that the objectives and programs related to adopting responsibility in higher education have changed over time, as it passes through three consecutive stages: system effectiveness, educational quality, and institutional creativity. Clarifying the extensions, determining the responsibility, and developing effective, integrated systems for responsibility are all required. This is because the higher education system is very important for society. The researcher of the present study believes that accreditation of universities means reinforcing the sense of responsibility. This sense of responsibility must be observed in three parties - the faculty members, the university administration, and the accreditation board. Thus, through evaluation, mastery in the workplace, continuous promotion, and quality in higher education can be achieved. Evaluating the faculty members is one of the mechanisms of accreditation, such that accreditation is performed through self-evaluation and the university itself is responsible for carrying out this evaluation (Darandari et al., 2008). A Survey for Investigating some Officers and Faculty Members' Opinions about the Procedures of Applying the Evaluation and Quality Assurance Operations in Saudi Universities. The fourteenth annual conference: Saudi Educational and Psychological Association, Al-Qasim, Saudi Arabia.

Sykes (2003) maintains that as far as the researcher of this study is concerned, it is necessary to evaluate the performance of the faculty member employing the criteria provided by the National Board for Evaluation and Accreditation. These criteria include the quality of education and research and the relationships between the educational institution and society. These criteria can only be met by evaluating the faculty member's performance in all areas because faculty members are among the most important input of the university and it is important to know their weaknesses and strengths. It is also important to work on improving and promoting the faculty 
member's performance in teaching, conducting research, and serving the society, so mastery and the desired quality can be achieved. The other method employed to enable faculty members to achieve quality in higher education is questioning. Adopting the responsibility principle by the faculty members of the university should be based on the questioning rule. In this case, the entity of the university can be protected. This entity is based on the principles and criteria of quality, and on the cooperation of those who are in charge of protecting the university (Darandari et al., 2008).

Therefore, adopting the responsibility principle for the faculty members according to the questioning rule can help achieve mastery in the workplace, which in turn, is the essence of the total quality. To possess this rule, continuity, justice, knowledge, power, sincerity, and competency must be present. Sincerity can only be present once the faculty member feels the burden of responsibility. Moreover, serious continuity requires one to be obligated to accomplish his given tasks. Therefore, employing the questioning rule means that those in charge of higher education and continuous education should be responsible for what they do. (Eaton, 2006).

The faculty member is to be monitored and yet is to take responsibility. The supervisors will also evaluate the faculty member's performance when accomplishing his tasks, including teaching, conducting research, and serving the communication and society. This responsibility is also deemed self-monitoring and self-responsibility. The faculty member is also accountable to God and others - students, the department director, colleagues, and the university administration. In this way, the evaluation system can be constructed based on the responsibility rule (Darandari et al., 2008).

\subsection{The Challenges Facing the Faculty Members in Applying the Responsibility Principle to Achieve Quality}

A study carried out by Al-Dobbi (2008) suggests that not planning continuously for programs in their general meaning, lack of the effective role that teachers are to play, and the prevalence of negative phenomena resulting from inadequate preparation are among the obstacles in achieving quality in education. Also, the teacher has lost his professional as well as social status. The trained and efficient human competencies can perceive the educational objectives and the demands of their society more than other individuals. According to a study conducted by Al-Eidroos (2010), among the obstacles in evaluating the faculty members based on the responsibility principle are the following, not associating the evaluation with responsibility by those who carry out the evaluation, weakness of self-monitoring among some faculty members, lack of an evaluation framework that is based on responsibility, weakness of the mechanisms for monitoring and questioning the evaluation procedure at university, and lack of awareness and perception of some faculty members about the fact that their work should comply with the responsibility principle.

\section{Results}

Based on the previous discussion, it is found that faculty members have a good awareness about their clear and transparent policies based on quality and the administration's competency. Also, it is found that the university adopts all quality and accreditation indicators and the administration of the university is concerned with the improvement and promotion of the faculty members' competencies. Moreover, it is noted that this is done in such a way that is aligned with the current changes and development because education aims at preparing human competencies that can cope with the fast changes. Importantly, the faculty members at Yarmouk University can achieve quality in higher education. With the results attained in this study, the current study recommends placing emphasis on teamwork, giving equal chance to all faculty members at university, emphasizing the necessity of providing developed, up-to-date means of instruction that align the advancement of science and technology, emphasizing the importance of transparent criteria for evaluating the performance, the presence of a clear policy at university to achieve quality, being obligated to work with the intent to serve the society and community, and improving the confidence among the faculty members, encouraging thinking and personal development, using scientific criteria for evaluating researches, using a mechanism to perceive the problems related to societal demands, using criteria for assessing national and international customers' satisfaction, and coordinating faculties, local and business markets, boards, and various foundations.

\section{Conclusions}

In a nutshell, the current study identifies the responsibility of the faculty members at Yarmouk University in achieving quality in higher education. The faculty members are regarded as pillars in building sound and systematic higher education with high quality. The area of responsibility of the faculty members in universities to achieve quality in higher education is considered one of the key issues that faculty members are required to make them come true.

\section{Acknowledgment}

I am also grateful to Ajloun National University for sponsoring my scientific research papers and their 
consistent support and assistance.

\section{REFERENCES}

[1] Abo Daf, Mahmood, Al-Wasifi, Khitam. (2007). The Quality of education from the Islamic perspective: Concepts and application. The second educational conference on the quality of education in Palestine. The Islamic University, Gaza.

[2] Al-Andigani, Najm Al-Din, Niazi, Hayat. (2007). The Total quality criteria. The Malaysian conference on the higher education: challenges and perspectives, Malaysia.

[3] Al-Harbi, Khalid. (2009). Education Quality in Preparing and Training the Teacher from the Islamic Perspective. [Unpublished Ph.D. Thesis]. Faculty of Education, Umm Al-Qura University.

[4] Al-Khatib, Mohammad. (2005). An Introduction to the Application of the Total Quality Criteria and Systems in Educational Institutions. The fourteenth annual meeting, Saudi Educational and Psychological Association, Al-Qasim, Saudi Arabia.

[5] Darandari, Ighbal, Houk, Tahereh. (2008). A survey for investigating some officers' and faculty members' opinions about the procedures of applying the evaluation and quality assurance operations in Saudi Universities. The fourteenth annual conference, Saudi Educational and Psychological Association, Al-Qasim, Saudi Arabia.

[6] Al-Dobbi, Laila. (2008). The obstacles and problems in achieving quality in education. Fourteenth annual meeting (quality in education). The Saudi Educational Sciences Association (Gaston).
[7] Al-Eidroos, Aghadir. (2010). A Proposal for Improving the System of Evaluating the Faculty Members' Performance at the Saudi Universities from the Viewpoint of Faculty Members. [Unpublished Ph.D. Thesis]. Umm Al-Qura University.

[8] Majid, Sowsan, Al-Ziadat, Mohammad. (2008). Quality and Accreditation for Public and University Institutions. Dar Al-Safa for publishing and distribution, Amman, Jordan.

[9] Ali, F., Zhou, Y., Hussain, K., Nair, P., and Ragavan, N. (2016). Does higher education service quality affect student satisfaction, image, and loyalty? A study of international students in Malaysian public universities. Quality Assurance in Education, 24(1), 70-90.

[10] Seyfried, M., \& Pohlenz, P. (2018). Assessing quality assurance in higher education: Quality managers' perceptions of effectiveness. European Journal of Higher Education, 8(3), 258-271.

[11] Steinhardt, I., Schneijderberg, C., Götze, N., Baumann, J., \& Krücken, G. (2017). Mapping the quality assurance of teaching and learning in higher education: The emergence of a specialty? Higher Education, 74(2), 221-237.

[12] Hu, X., Su, Y., \& Wang, T. (2019). Research on the whole teaching process evaluation and quality assurance system of higher vocational colleges. In IOP Conference Series: Materials Science and Engineering, 6(12), 3-16.

[13] Eaton, Judith S. (2006). Presidential perspectives on accreditation report of the CHEA presidents project. Retrieved on January 12, 2010. From www.chea.org.

[14] Sykes, Charles Edward. (2003). Community college administrator's perception of the accreditation process in the state of Illinois. [Unpublished Ph.D. Dissertation]. Union Institute and University, Ohio ProQuest Document ID.765-93741, Ann. 